\title{
Aging of Concrete Buildings and Determining the pH Value on the Surface of Concrete by Using a Handy Semi-Conductive pH Meter
}

\author{
Meng Heng and Katsuo Murata \\ Naruto University of Education, Naruto, Tokushima 772-8502, Japan
}

\begin{abstract}
A new method was devised for measuring the $\mathrm{pH}$ of a concrete surface by $\mathrm{pHBOY}-\mathrm{P} 2$ with a piece of filter paper by extracting the $\mathrm{pH}$ value from concrete. This is a simple and inexpensive method that does not damage the concrete building, and is easy to apply on concrete samples for monitoring. By using the method mentioned above, a drastic decrease of the $\mathrm{pH}$ value of concrete bridges and buildings has investigated. The method is environmentally friendly to detect the $\mathrm{pH}$ value change of concrete as an environmental sample investigation.
\end{abstract}

(Received March 3, 2004; Accepted May 27, 2004)

\section{Introduction}

The falling of concrete parts has recently caused major problems in our modern society. For instance, Japanese newspapers have initiated reports since July of 1999 that concrete parts of tunnels have dropped on Japanese bullet trains causing fear and injuries. Moreover, a journalist reviewed the case of a concrete crack in more detail in September, $2000 .{ }^{1}$ Spraying an alcohol solution of $1 \%$ phenolphthalein ${ }^{2,3}$ has frequently been used to check the neutralization of concrete. A pink color on the surface of concrete indicates it to still be basic. For example, Izumi et al. investigated the neutralization of concrete by using a phenolphthalein method. ${ }^{4}$ Morinaga and Kondou studied the neutralization of concrete and the corrosion of ferroconcrete. ${ }^{5}$ Kishitani and Kashino indicated a concept map of the $\mathrm{pH}$ slope and phenolphthalein method. ${ }^{6}$ Sergi and Glass recently analyzed cement pastes and concretes by a phenolphthalein endpoint method. ${ }^{7}$ Most of those studies qualitatively find the boundary between the neutralized and unneutralized parts by using a phenolphthalein solution. Some quantitative methods have been developed to investigate the neutralization of concrete ${ }^{8,9}$ in the laboratory. They are the Xray diffraction method, TG-DTA analysis, Electron Probe Micro Analysis (EPMA), and electrochemical analysis. The Xray diffraction method revealed the acid neutralization of a Portland cement mixture. ${ }^{10}$ A thermogravimetric analysis ${ }^{11}$ and a TG-DTA analysis ${ }^{12}$ were performed for autoclaved aerated concrete and in-situ concrete, respectively. An electrochemical analysis was applied to concrete materials ${ }^{13}$ and the study of corrosion inhibitation in concrete. ${ }^{14}$

Most of these methods use a bulky machine and apparatus, which make it very difficult to measure many in-situ concrete samples in the environment; also, the phenolphthalein method causes an undesired stain on the concrete.

The aim of the present study was to develop in-situ $\mathrm{pH}$ measurements of concrete surfaces outdoors. This new method is based on using a piece of filter paper and a handy semiconductive $\mathrm{pH}$ meter. It is a simple and inexpensive method.

\section{Experimental}

\section{Apparatus and reagents}

Shindengen Kougyou Co. pH-meter (pHBOY-P2) was used for measuring the $\mathrm{pH}$ value of samples. A Touretechno Co. UV-meter was used to monitor the UV radiation in the measurement place. Advantec Toyo filter paper (No. 5B) was the original filter paper used for filter paper 6-mm diameter size to fit the $\mathrm{pH}$ sensor part. Distilled water, a one-punch hole, tweezers, a stop watch, a black umbrella, cardboard, Kim wipers s-200, and brass (cloth washing brass) for cleaning the surface of concrete were used in the measurement.

\section{Procedure for a $\mathrm{pH}$ measurement}

A filter paper of 6-mm diameter was produced by a one-punch hole from filter paper No. 5B. It was placed on cleaned concrete surface. Distilled water, $100 \mu \mathrm{l}$ (micro liter), was dropped onto the filter paper of concrete samples. The filter paper was left for $15 \mathrm{~min}$. While the sample was drying, an additional $100 \mu \mathrm{l}$ of distilled water was added onto the concrete surface. The amount of distilled water needed depended on the concrete surface. The important clue was that the less was the water amount on the surface concrete, the greater was the amount of water that the paper sample could absorb. The punched 6-mm filter paper was dragged on the concrete surface by stainless-steel tweezers to make the pulp swell in order to absorb a greater amount of water, which was extracted from the concrete surface. After treating the filter paper sample for 15 min on the concrete surface, it was transferred to the sensor part of a pHBOY-P2 meter for a measurement. The value on the monitor was recorded after it became stable.

\section{Results and Discussion}

\section{Equilibrium time for the $\mathrm{pH}$ of a concrete surface}

Filter-paper samples were applied to concrete surfaces with distilled water, and the $\mathrm{pH}$ value was measured as a function of time. The test was repeatedly performed at the same place. In 


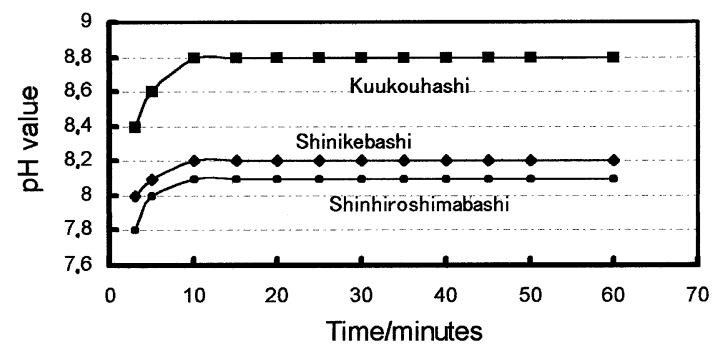

Fig. 1 Equilibrium time of $\mathrm{pH}$ concrete samples at three different bridges: Kuukouhashi, Shinikebashi and Shinhiroshimabashi $(\mathrm{pH}$ surface of concrete samples were measured and their equilibrium time were about 10 min after the experiment started. The equilibrium time was determined after 15 min through the study).

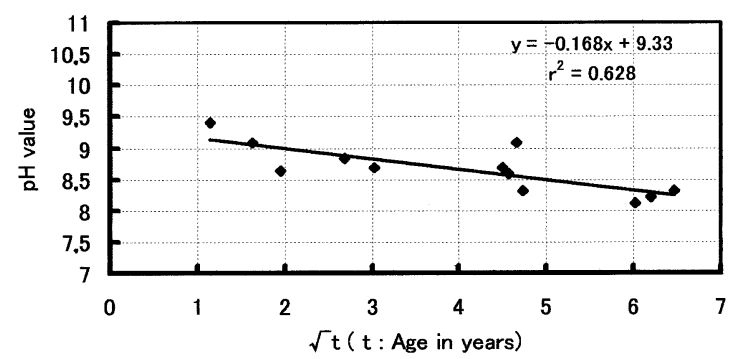

Fig. 2 Value of $\mathrm{pH}$ concrete bridges in mountain areas and root of their ages $(\mathrm{pH}$ value is the average of the $\mathrm{pH}$ of five different locations of the same concrete samples).

order to decide the equilibrium time in the measurement of the $\mathrm{pH}$ on the surface of concrete, the change in the $\mathrm{pH}$ with time was expressed as in Fig. 1. It needed at least $10 \mathrm{~min}$ to reach equilibrium, as shown in Fig. 1. All of the samples were measured after 15 min.

Measurement of the $\mathrm{pH}$ value in the depth of a concrete building

Concrete powder samples were collected by drilling at 1, 3, 5 and $8 \mathrm{~cm}$ in depth of a concrete bank at the seaside. A small amount of distilled water was added to the collected concrete powder. Punched filter papers were placed on it for $15 \mathrm{~min}$, as mentioned above. The basicity $(\mathrm{pH})$ of every different depth of the concrete was measured five times. The average values are given in Table 1. Samples in the depth of concrete below $1 \mathrm{~cm}$ deep, were shown to be near to $\mathrm{pH} 12$. This indicates that neutralization proceeded only in the vicinity of the surface of the concrete bank.

Comparison of the $\mathrm{pH}$ value of a new concrete with an old concrete Concrete blocks were prepared for comparisons with various concrete samples through the study. A freshly prepared concrete shows $\mathrm{pH}$ values above 11 , as given in Table 2, while old concrete from a seaside shows $\mathrm{pH}$ value below 10 . Old concrete buildings have undergone neutralization. It is known that the reason for neutralization can be mainly attributed to the carbonation of concrete buildings. ${ }^{15}$ People have added a huge amount, up to six billion tons, of $\mathrm{CO}_{2}$ to the atmosphere every year. ${ }^{16}$ Most of it comes from burning waste disposal and fossil fuel. Cement in the concrete is subject to hydration as shown by Eqs. (1) and (2) below. Formed calcium hydroxide reveals basic values of $\mathrm{pH} 12-13$. Neutralization of cement proceeds gradually by absorbing $0.03 \% \mathrm{CO}_{2}$ in the atmosphere, as in
Table 1 Surface of seawall concrete and its $\mathrm{pH}$ value, which varied with depth

\begin{tabular}{ccr}
\hline Depth/cm & pH in average & \multicolumn{1}{c}{ STDEV } \\
\hline 0 & 8.80 & $8.80 \pm 0.26$ \\
1 & 11.87 & $11.87 \pm 0.05$ \\
3 & 11.97 & $11.97 \pm 0.05$ \\
5 & 12.02 & $12.02 \pm 0.10$ \\
8 & 12.05 & $12.05 \pm 0.12$ \\
\hline
\end{tabular}

Table 2 Age and average $\mathrm{pH}$ value of surface concrete models and selected samples

\begin{tabular}{llcc}
\hline No. & \multicolumn{1}{c}{ Concrete } & $\begin{array}{c}\mathrm{pH} \text { value } \\
\text { (average) }\end{array}$ & Age (years) \\
\hline 1 & Liquid of cement mixture & 12.60 & 0 \\
2 & New concrete block & 11.20 & 0 \\
3 & Naruto University of Education, & 9.18 & 7.08 \\
& Cafeteria building & 6.84 & 23.7 \\
\hline
\end{tabular}

Eq. (3). Carbonation of cement progresses totally in Eq. (4). Neutralization due to carbonation that proceeds equally anywhere is under an atmosphere of $0.03 \% \mathrm{CO}_{2}$. However, neutralization of concrete buildings progresses more rapidly in the environment due to air pollution or acidic precipitation.

$$
\begin{aligned}
& 2(\mathrm{CaO})_{3} \mathrm{SiO}_{2}+6 \mathrm{H}_{2} \mathrm{O} \longrightarrow(\mathrm{CaO})_{3}\left(\mathrm{SiO}_{2}\right)_{2}\left(\mathrm{H}_{2} \mathrm{O}\right)_{3}+3 \mathrm{Ca}(\mathrm{OH})_{2} \\
& 2(\mathrm{CaO})_{2} \mathrm{SiO}_{2}+4 \mathrm{H}_{2} \mathrm{O} \longrightarrow(\mathrm{CaO})_{3}\left(\mathrm{SiO}_{2}\right)_{2}\left(\mathrm{H}_{2} \mathrm{O}\right)_{3}+\mathrm{Ca}(\mathrm{OH})_{2} \\
& \mathrm{Ca}(\mathrm{OH})_{2}+\mathrm{CO}_{2} \longrightarrow \mathrm{CaCO}_{3}+\mathrm{H}_{2} \mathrm{O} \\
& (\mathrm{CaO})_{3}\left(\mathrm{SiO}_{2}\right)_{2}\left(\mathrm{H}_{2} \mathrm{O}\right)_{3}+3 \mathrm{CO}_{2} \longrightarrow 3 \mathrm{CaCO}_{3}+2 \mathrm{SiO}_{2}+3 \mathrm{H}_{2} \mathrm{O}
\end{aligned}
$$

Measurement of the $\mathrm{pH}$ on the surface of various concrete buildings at different places in Kagawa and Tokushima

Measurements of the $\mathrm{pH}$ for concrete buildings of 111 samples were performed in Kagawa and Tokushima. Most of the samples were concrete bridges that were clearly old. It is postulated that neutralization of concrete buildings proceeds mainly via carbonation in mountain areas, while in cities and seaside areas additional affects would occur besides carbonation.

\section{Samples of mountain area}

The samples of mountain area included mountain ranges between Tokushima-Kagawa area (border of two prefectures). This location is surrounded by mountains as a sea windbreak. It has less transportation than in the city. Most of the bridges are located in Tokushima prefecture. By analyzing the data concerning the $\mathrm{pH}$ value of the concrete surface, it has been shown that the $\mathrm{pH}$ value of concrete became lower as the age of the concrete construction became older, as shown in Fig. 2. Some empirical equations ${ }^{17-19}$ were proposed that the thickness (cm) of neutralization was proportional to the square root of $t$ (year). Three treatments of data were compared in the plot of the $\mathrm{pH}$ of concrete against age: the first was square root of the year; the second was just the year; and the third was square of the year. The values of $r^{2}$ in the plot are $0.628,0.607$, and 0.546 , respectively. The plot of the $\mathrm{pH}$ on the surface of concrete against the root of the year has a higher correlation in 


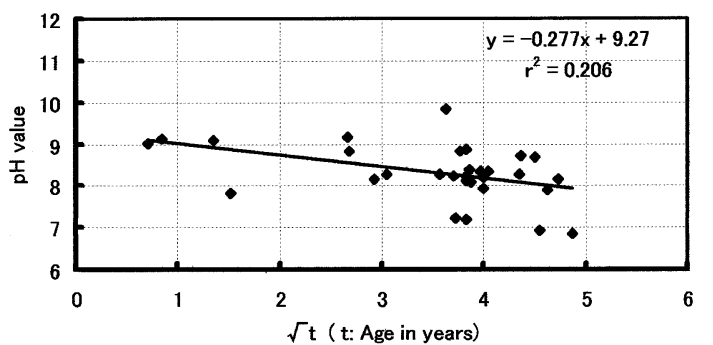

Fig. 3 Trends of the $\mathrm{pH}$ value and root of their ages for concrete samples in an island (Takashima island of Tokushima prefecture), Japan.

mountain areas among the comparison. The slope and variance $\left(r^{2}\right)$ is used to explain the correlation regression lines. Tokushima-Kagawa area is a mountain area that included of twelve bridges. Its graph showed a slope of -0.168 and a variance of $r^{2}=0.628$. This means that the $\mathrm{pH}$ decreased by 0.168 per square root of the year (Fig. 2), and 63\% of data plot was arranged on the regression line.

\section{Samples of seaside and Tokushima city area}

The sea area was Takashima, which is surrounded by the sea, and is located in Naruto city, Tokushima prefecture. Concrete samples were water gates, bridges and buildings of Naruto University of Education in the area. They showed a correlation plot of $r^{2}=0.206$ as scatter plots of $r^{2}$ varied in $1 \geq r^{2} \geq 0$. A slope of -0.277 was obtained from the equation $Y=-0.277 x+$ 9.27, as shown in Fig. 3. Its slope is 0.277 , which is greater than 0.168 of the mountain area. The $\mathrm{pH}$ values of the concrete bridges in the sea area and the city area are more changeable than those in the mountain area. They could have been affected by sea exposure, which showered and emitted sulfur compounds, like $\mathrm{SO}_{x}$ via $\left(\mathrm{CH}_{3}\right)_{2} \mathrm{~S}$ in the air. They later fell on concrete by acid rain and other kinds of precipitation. The air of this region contained $\mathrm{NO}_{\mathrm{x}}\left(\mathrm{NO}+\mathrm{NO}_{2}\right)$ and $\mathrm{SO}_{2}$ with averages of $0.020 \mathrm{ppm}$ and $0.008 \mathrm{ppm}$, respectively. ${ }^{20}$ The quantity of $\mathrm{SO}_{2}$ emitted from the ocean is 22-times higher than $\mathrm{NO}_{\mathrm{x}}$ emitted from the same souces. ${ }^{21,22}$ Therefore, the atmosphere of sea and seaside areas contain higher amounts of $\mathrm{SO}_{2}$ than that of the mountain area. The mass of $\mathrm{NO}_{\mathrm{x}}$ emitted per year is less than $40 \%$ of the mass of $\mathrm{SO}_{2}$ in the case of only fossil combustion. ${ }^{21,22}$ The number of inhabitants of the area has been increasing, and the amount of transportation has also been increasing. Consequently, the $\mathrm{NO}_{\mathrm{x}}$ in the air has become higher in concentration, as found in a study of Murata et al..$^{23-25}$ Otherwise, samples of Tokushima city area were exposed to the exhaust of vehicles heavier than other areas in the study. Hence, the concentration of $\mathrm{NO}_{\mathrm{x}}$ releasing in the air was higher than that in the other areas. All of these pollutants transformed to sulfuric and nitric acids in rain, snow, or hail, which have diverse affects on concrete buildings as a neutralized problem of the concrete, as shown in Eqs. (5) and (6). The later has a bigger scatter than the mountain area and sea area of data plots. It is considered that one of the reasons for the lower value of $r^{2}$ comes from acidic air pollution, which depends on the locations:

$$
\begin{aligned}
& \mathrm{Ca}(\mathrm{OH})_{2}+2 \mathrm{HNO}_{3} \longrightarrow \mathrm{Ca}\left(\mathrm{NO}_{3}\right)_{2}+2 \mathrm{H}_{2} \mathrm{O} \\
& \mathrm{Ca}(\mathrm{OH})_{2}+\mathrm{H}_{2} \mathrm{SO}_{4} \longrightarrow \mathrm{CaSO}_{4}+2 \mathrm{H}_{2} \mathrm{O}
\end{aligned}
$$

All data concerning the mountain, sea, and city areas are

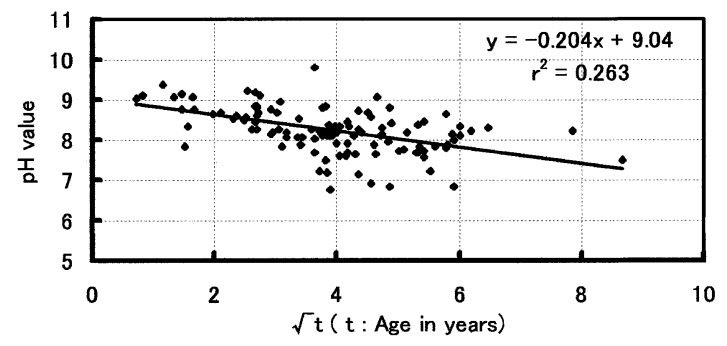

Fig. 4 Correlation regression line of the $\mathrm{pH}$ value of 111 concrete samples and the root of their ages.

summarized in Fig. 4. The result of the experiment clearly showed that the difference in the location of the concrete and the environmental pollution caused a rapid neutralization of concrete buildings. ${ }^{26}$

\section{Conclusion}

The data obtained in this study demonstrated that there was a correlation between the $\mathrm{pH}$ value of the concrete and the age of the concrete after construction. The older concrete buildings had lower $\mathrm{pH}$ values of the concrete surfaces. The changing rates of $\mathrm{pH} / \mathrm{year}$ of concrete construction in the sea and city areas were much higher than that in the mountain area. However, the correlation of the $\mathrm{pH}$ on the surface of the concrete and the aging in the sea and city area were lower than in the mountain area. This leads to the conclusion that the mountain area had less pollutant, so that the decrease in the $\mathrm{pH}$ value was slow along with its aging, whereas the $\mathrm{pH}$ of concrete constructions in the city and sea areas rapidly changed under a polluted air atmosphere. This was caused pollutants from the exhaust of vehicles and machines that run by fuel, and other kind of pollution emission. The pollutants that affected concrete included many forms of gases as well as various kinds of precipitation. This fact could be identified by a simple method without any damaging or destruction of the concrete. Therefore, it is an environmentally friendly method to investigate the changing $\mathrm{pH}$ of concrete in the environment. It is a portable meter that one can simply bring anytime and anywhere to investigate a concrete sample in the environment.

\section{References}

1. K. Sato, Mainichi Newspaper, 2000 Sept. 2, http://www.12.mainichi.co.jp/.

2. JIS K8799.

3. K. Kobayasi, "Kenzoubutuno Rekkashindanhou (Diagnostics in Deterioration of Building)", 1998, Morikitashoten, Tokyo, 19.

4. Oshida, Asai, I. Izumi, and H. Kasa, Abstract of Conference in Architectural Institute of Japan, 1983, 197.

5. S. Morinaga and T. Kondou, Abstract of Conference in Architectural Institute of Japan, 1974, 355.

6. K. Kishitani and N. Kashino, Report in Architectural Institute of Japan, 1979, No. 283, 11.

7. G. Sergi and G. K. Glass, Corrosion Sci., 2000, 42, 2043.

8. I. Izumi, T. Kita, and T. Maeda, "Chuseika (Neutralization)", 1988, Gihoudoh, Tokyo, 5.

9. K. Kobayasi, "Kenzoubutuno Rekkashindanhou (Diagnostics in Deterioration of Building)", 1998, 
Morikitashoten, Tokyo, 79.

10. C. Giampaolo, S. Lo Mastro, A. Polettini, and P. Sirini, Cement and Concrete Res., 2002, 32, 769.

11. L. J. Parrott and D. C. Killoh, Cement and Concrete Res., 1989, 19, 649 .

12. F. Matsushita, Y. Aono, and S. Shibata, Cement and Concrete Res., 2000, 30, 1741.

13. G. K. Glass and N. R. Buenfeld, Cement and Concrete Res., 1999, 29, 1681.

14. G. K. Glass, B. Reddy, and N. R. Buenfeld, Corrosion Sci., 2000, 42,1587

15. I. Izumi, T. Kita, and T. Maeda, "Chuseika (Neutralization)", 1988, Gihoudoh, Tokyo, 1.

16. A. D. Fredericks, "Simple Nature Experiments with Everyday Materials", 1995, Sterling Pub., New York.

17. I. Izumi, T. Kita, and T. Maeda, "Chuseika (Neutralization)", 1988, Gihoudoh, Tokyo, 34.

18. M. Hamada, Sement-konkurihto (cement·concrete), 1969,
No. 272.

19. A. Yoda, Sement·konkurihto (cement-concrete), 1982, No. 429.

20. Health and Environmental Center of Tokushima, "Report of air pollution monitoring", 1985, Vol. 9, 15.

21. P. A. Spiro, D. J. Jacob, and J. A. Logan, J. Geophys. Res., 1992, 97, 6023.

22. C. L. Stanitski, L. P. Eubanks, C. H. Middlecamp, and W. J. Stratton, "Chemistry in Context: Applying Chemistry to the Society”, 2000, McGraw-Hill, New York, 229.

23. K. Murata and S. Yamashita, Nippon Kagaku Kaishi, 1991, $5,491$.

24. K. Murata, S. Yamashita, N. Ogawa, K. Hayakawa, and H. Taniguchi, Bunseki Kagaku, 1994, 43, 203.

25. K. Murata, K. Iizuna, S. Yamashita, H. Taniguchi, and Y. Tanaka, Bunseki Kagaku, 1994, 43, 1033.

26. K. Kobayashi, "Konkuritoga abunai (crisis of concrete degradation)", 1999, Iwanamishoten, Tokyo, 36. 